and his proposal to give to "alum" the name atolan-telminajafin-weso.

Chemical Society, April I4. Charles E. Groves.

P.S. - I need scarcely say how cordially I concur with $\mathrm{Mr}$. W. F. Kirby's exceedingly apposite remark that no system of transliteration should be adopted offhand without full dis. cussion.

WrTH reference to the scheme of Russian transliteration propounded on p. 397 of NATURE (vol. xli.), I should be obliged if the editor of NATURE would allow me the opportunity of suggesting that different principles of respelling foreign languages in English might possibly be adopted with advantage for different purposes. The scheme referred to is one of strict transliteration in other words, the aim is to represent the letters of a foreign alphabet uniformly by the same letters or combinations of letters in the English alphabet. For the purpose of drawing up lists of titles of books and papers in a foreign language - the purpose obviously kept in view by the propounders of the new Russian scheme-this principle is no doubt the best. It is the only one that makes it easy to consult a Russian dictionary. But it does not follow that the principle of strict transliteration is the best to adopt for foreign proper names occurring in a language different from that to which they belong. The third of the rules adopted by the Council of the Royal Geographical Society for geographical orthography is as follows: "The true sound of the word a locally pronounced will be taken as the basis of the spelling" (Proc. Roy. Geog. Soc., 1885, p. 535). This rule is inconsistent with any scheme of strict transliteration. I can imagine that two views may be held as to its propriety. Unquestionably there are difficulties in applying it, but surely for the purpose for which the rule was adopted it is at least defensible and worthy of serious discussion.

Even if it should be recognized, however, that it is desirable that one principle of conversion into a foreign alphabet should be adopted for one purpose, another for another, it will, I think, be generally admitted to be a matter of the greatest importance that an agreement should be come to among all concerned in such conversions as to those points which might be held in common on either system of conversion. All schemes of transliteration in the strict sense of the term are based on phonetic rules. The aim in all is to render the letters of one alphabet by the letters and signs most appropriately representing their normal sounds in another. It is the departures from the normal sounds that are disregarded. Now a uniform system of representing sounds, so far as it is at all desirable to represent foreign sounds in English, if devised with sufficiently wide regard to the requirements of different languages, would be of great use as a system to be followed for every word or name on the principle of phonetic respelling and to be adopted as the basis of every scheme of transliteration.

April 22.

Geo. G. Chisholm.

\section{On some Decomposed Flints from Southbourne-on-Sea.}

THE curiously decomposed flint-pebbles which occur in the cliffs between Boscombe and Southbourne-on-Sea have not, so far as I have been able to ascertain, yet received the attention they deserve, and, with a view of obtaining other opinions before the completion of a paper on the subject, I venture briefly to offer mine.

I will not now deal generally with all the pebbles in the horizon alluded to, but specifically with some of unusual interest which occur at a certain point in the cliff, as these represent an extreme type of decomposition to which most of the less-altered pebbles may be found gradating. These type-pebbles occur in the cliff a short distance to the east of the pier at Southbourneon-Sea, and present all the characteristic features of a littoral deposit.

A section of the cliff at this point shows :-

\section{Blown sand}

Brown loam, passing ${ }_{\text {down }}$ into $\dddot{\text { lighter-coloured }}$ sandy gravel containing angular and sub-angular yellow and krown flints without any definite mode of deposition ... ... $\quad \ldots \quad \ldots$

At the base of this, and resting on pure quatzose from flints, is a definite and more or less horizontal layer of rounded and decomposed flint-pebbles of about one pebble in thickness, partially embedded in the white sand on which they rest, and covered by the clastic matter of the bed above.

While some of these pebbles are apparently unaffected, most of them are eroded in a remarkable manner, having large portions of their substance removed; and others, though retaining their original form, are completely changed throughout their mass into a soft, white substance (crystalline silica) macroscopically like chalk, and as easily cut or sawn through. The largest wholly-decomposed specimen I have been able to procure measures 14 inches around its greatest circumference.

It is remarkable that these fint-wrecks preserve their original form and detail to such a degree of perfection that in most cases the soft surfaces retain the crescentic markings (mastoid) of incipient conchoidal fracture which resulted originally from the percussion due to wave-action.

As far as I am at present able to judge, the silica originally composing these pebbles was of two distinct kinds-a bluish. black, or more stable form (superior crystalline development), and a light-coloured, or less stable form (inferior crystalline de. velopment); for, in the specimens I have procured, the bluishblack variety does not appear to be abnormally affected, while the lighter-coloured variety is nearly always partially or completely decomposed. The wholly-decomposed pebbles would, therefore, have been formed of the unstable variety, while those eroded only would have been formed of a combination of the two, the stable portion now remaining.

My supposition seems to be strengthened by the evidence obtained from the banded flints, which are very plentiful here. These banded flints are formed of alternating zones of the two varieties, and in many cases the unstable form has been so decomposed as to leave only successive zones of the more stable form fitting loosely one into the other like a nest of boxes, and as easily separable. Notwithstanding this fact these unstable zones -before decomposition-are apparently as well able to withstand mechanical erosion as the stable zones, a conclusion arrived at through having some of these banded flints subjected to the action of the sand-blast for 15 minutes without any "ridging" taking place.

That the decomposition of these particular flint-pebbles must have taken place prior to the deposition of the superincumbent bed of clastic material is proved, I think, by the fact that none of the flints composing this bed appear to be decomposed, even the smallest chips being comparatively unaffected.

From this and other facts observed, I gather that the decomposition of these pebbles must have taken place when they were exposed to the air, but I do not think atınospheric influences alone would be sufficient to account for the evident rapidity and effectiveness of the process; we must seek a special cause for an unusual effect.

I venture to suggest that the solvent which has in this case removed the colloidal silica was derived from decaying sea-weed, and other organic matter, cast up from time to time by the waves upon this (then) pebbly beach. Large masses of sea-weed cast up by storm-waves take a considerable time to decompose, and during such period is it not possible that they might produce alkaline solutions, or-as has been suggested to me by Dr. Irving-combinations of ammonia and organic acids? Either of these is a well-known solvent of colloidal silica. The action of such solvents might have been accelerated by the mechanical process through which most of these pebbles passed prior to their final state of rest, viz. the action of the sca-waves in producing the mastoid structure already alluded to, this molecular disruption no doubt facilitating the penetration of the solvent to the very heart of the pebble. It is worthy of note, too, that in some of the eroded specimens procured, the remaining unaffected parts are almost entirely free from these incipient fractures, a fact which-if we ignore the supposed variation in the stability of the silica-suggests the necessity for a combination of the chemical and mechanical causes to produce the effects observed.

I have dealt here with a special case only, in the hope that my suggestions may be found applicable to the many in which we see abnormal decomposition occurring in the flint-pebbles of littoral deposits, and which appears to be distinct from the "weathering" so frequently seen occurring to considerable depths in the exposed flints of deposits other than littoral. Bournemouth, April 16. Cecil Carus-Wilson.

\section{Doppler's Principle.}

As a student I should be much obliged to any reader for an explanation of the following difficulty. In considering Doppler's 